\title{
Respiratory failure
}

\author{
C. Roussos, A. Koutsoukou
}

Respiratory failure. C. Roussos, A. Koutsoukou. (C) ERS Journals Ltd 2003.

ABSTRACT: Respiratory failure occurs due mainly either to lung failure resulting in hypoxaemia or pump failure resulting in alveolar hypoventilation and hypercapnia. Hypercapnic respiratory failure may be the result of mechanical defects, central nervous system depression, imbalance of energy demands and supplies and/or adaptation of central controllers.

Hypercapnic respiratory failure may occur either acutely, insidiously or acutely upon chronic carbon dioxide retention. In all these conditions, pathophysiologically, the common denominator is reduced alveolar ventilation for a given carbon dioxide production.

Acute hypercapnic respiratory failure is usually caused by defects in the central nervous system, impairment of neuromuscular transmission, mechanical defect of the ribcage and fatigue of the respiratory muscles.

The pathophysiological mechanisms responsible for chronic carbon dioxide retention are not yet clear. The most attractive hypothesis for this disorder is the theory of "natural wisdom". Patients facing a load have two options, either to push hard in order to maintain normal arterial carbon dioxide and oxygen tensions at the cost of eventually becoming fatigued and exhausted or to breathe at a lower minute ventilation, avoiding dyspnoea, fatigue and exhaustion but at the expense of reduced alveolar ventilation. Based on most recent work, the favoured hypothesis is that a threshold inspiratory load may exist, which, when exceeded, results in injury to the muscles and, consequently, an adaptive response is elicited to prevent and/or reduce this damage. This consists of cytokine production, which, in turn, modulates the respiratory controllers, either directly through the blood or probably the small afferents or via the hypothalamicpituitary-adrenal axis. Modulation of the pattern of breathing, however, ultimately results in alveolar hypoventilation and carbon dioxide retention.

Eur Respir J 2003; 22: Suppl. 47, 3s-14s.
Dept of Critical Care and Pulmonary Services, University of Athens Medical School, Evangelismos Hospital, Athens, Greece.

Correspondence: C. Roussos

Dept of Critical Care

Evangelismos Hospital

45-47 Ipsilandou Street

GR-106 76 Athens

Greece

Fax: 302107216503

E-mail: croussos@cc.uoa.gr

Keywords: $\beta$-Endorphins

cytokines

hypercapnia

pump failure

respiratory muscles fatigue

Received: April 72003

Accepted after revision: August 72003

This study was supported by the Thorax Foundation, Athens, Greece
Respiratory failure is a condition in which the respiratory system fails in one or both of its gas exchange functions, i.e. oxygenation of and/or elimination of carbon dioxide from mixed venous blood. It is conventionally defined by an arterial oxygen tension $\left(\mathrm{Pa}, \mathrm{O}_{2}\right)$ of $<8.0 \mathrm{kPa}(60 \mathrm{mmHg})$, an arterial carbon dioxide tension $\left(\mathrm{Pa}, \mathrm{CO}_{2}\right)$ of $>6.0 \mathrm{kPa}(45 \mathrm{mmHg})$ or both. Therefore, the diagnosis of respiratory failure is a laboratory one, but the important point to emphasise is that these cut-off values are not rigid; they simply serve as a general guide in combination with the history and clinical assessment of the patient.

The respiratory system can be said to consist of two parts: the lung, i.e. the gas-exchanging organ, and the pump that ventilates the lungs [1]. The pump consists of the chest wall, including the respiratory muscles, the respiratory controllers in the central nervous system (CNS) and the pathways that connect the central controllers with the respiratory muscles (spinal and peripheral nerves). Failure of each part of the system leads to a distinct entity (fig. 1). In general, failure of the lung caused by a variety of lung diseases (e.g. pneumonia, emphysema and interstitial lung disease) leads to hypoxaemia with normocapnia or hypocapnia (hypoxaemic or type I respiratory failure). Failure of the pump (e.g. drug overdose) results in alveolar hypoventilation and hypercapnia (hypercapnic or type II respiratory failure). Although there is coexistent hypoxaemia, the hallmark of ventilatory failure is the increase in $\mathrm{Pa}, \mathrm{CO}_{2}$. Undoubtedly, both types of respiratory failure may coexist in the same patient, as, for example, in patients with chronic obstructive pulmonary disease (COPD) and carbon dioxide retention, or in those with severe pulmonary oedema or asthmatic crisis, who first develop hypoxaemia and, as the disease persists or progresses, hypercapnia appears.

The various types of respiratory failure are presented in a gas tension diagram (fig. 2), which illustrates the various pathways. The solid line represents a respiratory exchange ratio of 0.8 . The parallel dotted line shows the corresponding

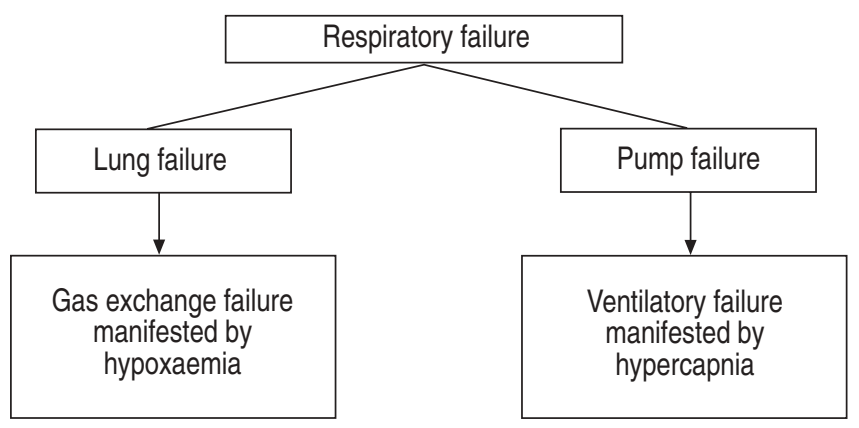

Fig. 1.-Types of respiratory failure. The respiratory system can be considered as consisting of two parts: 1) the lung; and 2) the pump. 


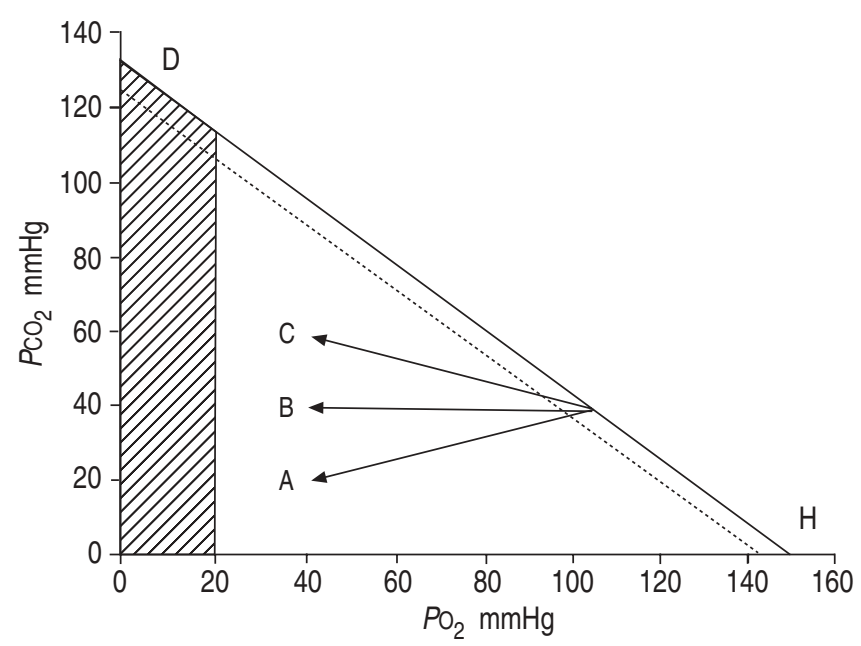

Fig. 2. - Relation between alveolar oxygen $\left(\mathrm{PO}_{2}\right)$ and carbon dioxide $\left(\mathrm{PCO}_{2}\right)$ tension when breathing air (- inspiratory oxygen fraction $21 \%)$. The slope of the line depends on the respiratory exchange ratio; in this example, it is assumed to be 0.8 . Arterial $P_{\mathrm{O}_{2}}(\cdots \cdots \cdots \cdots)$ is less than alveolar $\mathrm{PO}_{2}$; the difference assumed here is $5 \mathrm{mmHg}$. A-C: direction of changes in alveolar gas tensions in various lung diseases. $\mathbb{\nabla}$ : range of arterial $P_{\mathrm{O}_{2}}$ normally incompatible with prolonged survival $(1 \mathrm{mmHg}=0.133 \mathrm{kPa})$.

$\mathrm{Pa}, \mathrm{O}_{2}$ and $\mathrm{Pa}, \mathrm{CO}_{2}$ with an alveolar to arterial oxygen difference $\left(D \mathrm{~A}-\mathrm{aO}_{2}\right)$ of $\sim 0.67 \mathrm{kPa}(5 \mathrm{mmHg})$, as occurs in normal lung. When a normal subject hyperventilates, alveolar oxygen $\left(\mathrm{PA}, \mathrm{O}_{2}\right)$ and carbon dioxide $\left(\mathrm{PA}, \mathrm{CO}_{2}\right)$ tension and $P a, O_{2}$ and $P a, C_{2}$ move down the slope in the direction indicated by the letter $\mathrm{H}$, with rises in $\mathrm{PA}, \mathrm{O}_{2}$ and $\mathrm{Pa}, \mathrm{O}_{2}$ and falls in $\mathrm{PA}, \mathrm{CO}_{2}$ and $\mathrm{Pa}, \mathrm{CO}_{2}$. When hypoventilation occurs, in the normal subject, due to drug overdose for example, $\mathrm{PA}, \mathrm{O}_{2}$ and $\mathrm{Pa}, \mathrm{O}_{2}$ and $\mathrm{PA}, \mathrm{CO}_{2}$ and $\mathrm{Pa}, \mathrm{CO}_{2}$ move up the slope in the direction shown by the letter $\mathrm{D}$, with falls in $\mathrm{PA}, \mathrm{O}_{2}$ and $\mathrm{Pa}, \mathrm{O}_{2}$ and rises in $P A, C O_{2}$ and $P a, C_{2}$. It can be seen that, in the normal lung, when hypercapnia occurs (as in the case of alveolar hypoventilation due to $\mathrm{CNS}$ depression), $\mathrm{Pa}, \mathrm{O}_{2}$ cannot fall to very low levels. For example, when $P A, \mathrm{CO}_{2}$ increases from $5.3(40 \mathrm{mmHg})$ to $\sim 10.6 \mathrm{kPa}(80 \mathrm{mmHg}), \quad P A, \mathrm{O}_{2}$ decreases from $\sim 13.3(100 \mathrm{mmHg})$ to $\sim 8.0 \mathrm{kPa}(60 \mathrm{mmHg})$. Assuming a $D A-a O_{2}$ of $0.67-1.3 \mathrm{kPa}(5-10 \mathrm{mmHg})$, the $\mathrm{Pa}, \mathrm{O}_{2}$ is $\sim 5.3-6.7 \mathrm{kPa}(40-50 \mathrm{mmHg})$. Thus, when the lung is normal, a severe degree of alveolar hypoventilation, resulting in marked carbon dioxide retention, is not associated with excessive hypoxaemia. In lung diseases, however, due to increased $D A-\mathrm{aO}_{2}$, the same conditions lead to arterial hypoxaemia. Arrow A, in figure 2, shows a large $\mathrm{DA}-\mathrm{aO}_{2}$ (the horizontal distance between arrow A and alveolar line $\mathrm{D}-\mathrm{H}$ ), which is commonly observed in patients with pneumonia, atelectasis or acute respiratory distress syndrome (ARDS). Hyperventilation in these patients leads to very low $\mathrm{Pa}, \mathrm{CO}_{2}$. Line $\mathrm{B}$ depicts the pathway of patients with interstitial lung disease or pure emphysema. Line $\mathrm{C}$ depicts a mixed state in a patient with lung disease (hypoxaemia) and inadequate alveolar ventilation $\left(V^{\prime} \mathrm{A}\right)$. In severe cases (tip of arrow), hypoxaemia is dominant despite hypercapnia and the situation is certainly more dangerous than in pure hypoventilation at an equal $\mathrm{Pa}, \mathrm{CO}_{2}$. Patients usually reach line $\mathrm{C}$ starting from line A or B. Patients with COPD or end-stage interstitial lung disease who have remained along the $\mathrm{B}$ arrow for a long time move to arrow $\mathrm{C}$ as a result of alveolar hypoventilation. Similarly, patients with a gas-exchange abnormality, as shown by arrow A (acute asthma attack or pulmonary oedema), may move towards arrow $\mathrm{B}$ or $\mathrm{C}$ as the central controllers or respiratory muscles, or both, become unable to maintain adequate ventilation.

\section{Pathophysiology of respiratory failure}

\section{Hypoxaemic (type I) respiratory failure}

Four pathophysiological mechanisms account for the hypoxaemia seen in a wide variety of diseases: 1) ventilation/ perfusion inequality, 2) increased shunt, 3) diffusion impairment, and 4) alveolar hypoventilation [2]. Ventilation/perfusion mismatching is the most common mechanism and develops when there is decreased ventilation to normally perfused regions or when there are lung regions with a greater reduction in ventilation than in perfusion. With shunt, either intrapulmonary or intracardiac deoxygenated mixed venous blood bypasses ventilated alveoli, resulting in "venous admixture". Diseases that increase the diffusion pathway for oxygen from the alveolar space to the pulmonary capillaries, decrease capillary surface area or shorten the transit time of the blood through the pulmonary capillaries prevent complete equilibration of alveolar oxygen with pulmonary capillary blood.

In the absence of underlying pulmonary disease, hypoxaemia accompanying hypoventilation is characterised by normal $\mathrm{DA}-\mathrm{aO}_{2}$. In contrast, disorders in which any of the other three mechanisms are operative are characterised by broadening of the alveolar/arterial gradient resulting in severe hypoxemia.

Although changes in $V^{\prime}$ A can change $P \mathrm{a}, \mathrm{CO}_{2}$ considerably, this is not so for $P \mathrm{a}, \mathrm{O}_{2}$. Increases in $V^{\prime} \mathrm{A}$ modestly increase $\mathrm{Pa}, \mathrm{O}_{2}$. Owing to the sigmoidal shape of the oxyhaemoglobin dissociation curve, any effect of increasing ventilation on oxygen saturation is minimal above $\mathrm{Pa}_{2} \mathrm{O}_{2}$ of $7.3-8.0 \mathrm{kPa}$ (55-60 $\mathrm{mmHg}$. Hypoxaemia resulting from ventilation/perfusion inequality or diffusion abnormalities can easily be corrected by supplementing inspired oxygen, whereas even very high concentrations of inspired oxygen cannot correct hypoxaemia induced by increased pure shunt.

\section{Hypercapnic (type II) respiratory failure}

The respiratory equation. The volume of carbon dioxide eliminated per minute (which in a steady state is equal to that produced by the body $\left.\left(V^{\prime} \mathrm{CO}_{2}\right)\right)$ is dependent on the concentration of carbon dioxide in alveolar gas and on $V^{\prime} \mathrm{A}$. This is obvious, since the conducting airways do not exchange gas. Thus $V^{\prime} \mathrm{CO}_{2}=V^{\prime} \mathrm{A} \times$ alveolar $\mathrm{CO}_{2}$ concentration or alveolar $\mathrm{CO}_{2}$ concentration $=V^{\prime} \mathrm{CO}_{2} / V^{\prime} \mathrm{A}$. Alveolar $\mathrm{CO}_{2}$ concentration is the concentration of $\mathrm{CO}_{2}$ in the alveolar gas. Gas concentration is converted to gas pressure (Pgas) by the equation: Pgas $(\mathrm{mmHg})=(\%$ concentration $\times($ barometric pressure-water vapour) $/ 100$. At sea level, barometric pressure is 670 and water vapour pressure at $37^{\circ} \mathrm{C}$ is $47 \mathrm{mmHg}$. It follows that $P$ gas $(\mathrm{mmHg})=\%$ concentration $\times 713 / 100$.

By using factor $k(0.863)$, the constant of proportionality, the "respiratory equation" is obtained, which relates $V^{\prime}$ A to $\mathrm{Pa}, \mathrm{CO}_{2}$ :

$$
P \mathrm{a}, \mathrm{CO}_{2}=k V^{\prime} \mathrm{CO}_{2} / V^{\prime} \mathrm{A} .
$$

Since $V^{\prime} \mathrm{A}=V^{\prime} \mathrm{E}-V^{\prime} \mathrm{ds}$, where $V^{\prime} \mathrm{E}$ is minute ventilation and $V^{\prime} \mathrm{ds}$ dead space ventilation, this relation may be expressed as:

$$
\begin{aligned}
P_{\mathrm{a}, \mathrm{CO}_{2}} & =k V^{\prime} \mathrm{CO}_{2} /\left(V^{\prime} \mathrm{E}-V^{\prime} \mathrm{ds}\right) \\
& =k V^{\prime} \mathrm{CO}_{2} /\left(V \mathrm{~T} f \mathrm{R}\left(1-V^{\prime} \mathrm{ds} / V_{\mathrm{T}}\right)\right),
\end{aligned}
$$

where $V \mathrm{~T}$ is tidal volume and $f \mathrm{R}$ respiratory frequency.

Equation 2 states that the $P \mathrm{a}, \mathrm{CO}_{2}$ rises if $V^{\prime} \mathrm{CO}_{2}$ increases 
(e.g. hyperthermia) at constant $V^{\prime} \mathrm{A}$, or when, at a constant $V^{\prime} \mathrm{CO}_{2}, V^{\prime}$ A decreases by virtue of: 1) a rise in $V^{\prime} \mathrm{ds} / V \mathrm{~T}$ (by increasing $V^{\prime} \mathrm{ds}$, decreasing $V \mathrm{~T}$ or both), 2) a decrease in $V^{\prime} \mathrm{E}$, and 3) both an increase in $V^{\prime} \mathrm{ds} / V \mathrm{~T}$ and a decrease in $V^{\prime} \mathrm{E}[3,4]$.

In daily clinical practice, as a patient becomes hypercapnic, more than one factor generally contributes to the rise in $\mathrm{Pa}, \mathrm{CO}_{2}$.

Carbon dioxide production. For a young adult, $V^{\prime} \mathrm{CO}_{2}$ is $\sim 200 \mathrm{~mL} \cdot \mathrm{min}^{-1}$ (or $110 \mathrm{~mL} \cdot \mathrm{m}^{2}$ in males and $96 \mathrm{~mL} \cdot \mathrm{m}^{2}$ in females). $V^{\prime} \mathrm{CO}_{2}$ increases during hyperthermia by $\sim 14 \%$ for each degree Celsius rise in temperature, particularly during muscular activity. During inspiratory resistive breathing, the respiratory muscles, in this respect, may show a $V^{\prime} \mathrm{CO}_{2}$ of 700-800 $\mathrm{mL} \cdot \mathrm{min}^{-1}$ [5]. In the same manner, shivering or an increase in muscle tone, as occurs in tetanus, leads to excessive $V^{\prime} \mathrm{CO}_{2}$, with an up to three-fold increase, whereas muscular exercise may increase $V^{\prime} \mathrm{CO}_{2}>10$-fold. Under normal conditions, an increase in $V^{\prime} \mathrm{CO}_{2}$ is detected early by the CNS and is then easily compensated for by increasing $V^{\prime} \mathrm{E}$ to maintain a normal $\mathrm{Pa}, \mathrm{CO}_{2}$. However, if a patient's ventilatory capacity is impaired, an increase in $V^{\prime} \mathrm{CO}_{2}$ greatly stresses the ventilatory system and leads to an increase in $\mathrm{Pa}, \mathrm{CO}_{2}$.

Alveolar ventilation. Equations 1 and 2 imply that, at constant $V^{\prime} \mathrm{CO}_{2}$ and a given $V^{\prime} \mathrm{ds}, V^{\prime} \mathrm{A}$ changes when $V \mathrm{~T}$ or $f \mathrm{R}$ are varied either at constant or reduced total ventilation. This means that there are four possibilities: 1) unchanged total ventilation with decreased $f \mathrm{R}, 2$ ) unchanged total ventilation with increased $f \mathrm{R}, 3$ ) decreased total ventilation with decreased $f \mathrm{R}$, or 4 ) decreased $V \mathrm{~T}$.

Under conditions of unchanged total ventilation and decreased $f \mathrm{R}$, for $V^{\prime} \mathrm{E}$ to remain unchanged, $V \mathrm{~T}$ must increase. This decreases $V^{\prime} \mathrm{ds} / V \mathrm{~T}$, thereby increasing $V^{\prime} \mathrm{A}$ and decreasing $\mathrm{Pa}, \mathrm{CO}_{2}$.

Under conditions of unchanged total ventilation and increased $f \mathrm{R}$, for $V^{\prime} \mathrm{E}$ to remain unchanged, $V \mathrm{~T}$ must decrease. Such a change, however, increases the $V^{\prime} \mathrm{ds} / V \mathrm{~T}$ ratio and, therefore, $V^{\prime} \mathrm{A}$ decreases and $\mathrm{Pa}, \mathrm{CO}_{2}$ increases. In the clinical setting, rapid, shallow breathing may well explain carbon dioxide retention in patients with COPD.

Under conditions of decreased total ventilation and decreased $f \mathrm{R}$, the reduction in $f \mathrm{R}$ alone, without affecting $V^{\prime} \mathrm{ds} / V \mathrm{~T}$, leads to a certain decrease in $V^{\prime}$ A by virtue of a reduction in $V^{\prime} \mathrm{E}$.

Under conditions of decreased total ventilation and decreased $V \mathrm{~T}$, there is a reduction in $V^{\prime} \mathrm{E}$ caused by reducing the $V \mathrm{~T}$ (without reducing $f \mathrm{R}$ ), which results in an increase in $V^{\prime} \mathrm{ds} / V \mathrm{~T}$, and, consequently, in a rise in $\mathrm{Pa}, \mathrm{CO}_{2}$. Thus, the drop in $V^{\prime} \mathrm{A}$ is expected to be more pronounced than in the aforementioned cases.

Pathophysiology of ventilatory pump failure. There are three major causes of pump failure leading to hypercapnia [6]. 1) The output of the respiratory centres controlling the muscles may be inadequate (anaesthesia, drug overdose and diseases of the medulla), resulting in a central respiratory drive that is insufficient for the demand, or the respiratory centres may reflexively modify their output in order to prevent respiratory muscle injury and avoid or postpone fatigue. 2) There may be a mechanical defect in the chest wall, as is the case in flail chest, diseases of the nerves (Guillain-Barré syndrome) and anterior horn cells (poliomyelitis), or diseases of the respiratory muscles (myopathies). Severe hyperinflation, with flat diaphragm and reduced mechanical action of the inspiratory muscles, as in acute asthmatic attack, is one of the most common causes of impaired mechanical performance of the inspiratory muscles. 3) When working under excessive inspiratory load, the inspiratory muscles may become fatigued, i.e. they become unable to continue to generate an adequate pleural pressure despite an appropriate central respiratory drive and an intact chest wall.

It is obvious that, when there is insufficient activation from the CNS, either temporally (e.g. anaesthesia and overdose) or permanently (e.g. diseases of the medulla), respiratory efforts are inadequate and hypoventilation ensues.

Motor output emanating from the CNS needs to be transferred to the respiratory muscles, a process requiring anatomical and functional adequacy of the spinal cord, peripheral nerves and neuromuscular junction. Any disorder along this pathway results in insufficient inflation of the ribcage inadequate to generate subatmospheric pressure, which is essential for the air to flow into the lungs. Mechanical defects of the chest wall (flail chest, kyphoscoliosis and hyperinflation) are entities that predispose to alveolar hypoventilation since they impose additional work on the inspiratory muscles, which have to displace the noncompliant chest wall and lungs.

Since hyperinflation, commonly occurring in diseases characterised by airways obstruction and loss of elastic recoil of the lungs, has multiple adverse effects on inspiratory muscle function, it deserves to be discussed separately.

For humans to breathe spontaneously, the inspiratory muscles must generate sufficient force to overcome the elastic and resistive load of the respiratory system. Furthermore, the inspiratory muscles should be able to sustain the above mentioned load over time and adjust $V^{\prime} \mathrm{E}$ in such a way that there is adequate gas exchange. Fatigue is the inability of the respiratory muscles to continue to generate sufficient pressure to maintain $V^{\prime}$ A [6]. Fatigue should be distinguished from weakness, which is a fixed reduction in force generation not reversible by rest, although muscle weakness may predispose to muscle fatigue.

Fatigue occurs when the energy supply to the respiratory muscles does not meet the demands. Factors predisposing to respiratory muscle fatigue are those that increase inspiratory muscle energy demands and/or decrease energy supplies [7]. Energy demands are determined by the work of breathing and the strength and efficiency of the inspiratory muscles (fig. 3)

The work of breathing increases proportionally with the mean pressure developed by the inspiratory muscles per breath (mean tidal pressure $(P \mathrm{I})$ ), expressed as a fraction of maximum inspiratory pressure $(P \mathrm{I}, \max ), V^{\prime} \mathrm{E}$, duty cycle (inspiratory time $(t \mathrm{I}) /$ total respiratory cycle $(t$ tot $)$ ) and mean inspiratory flow rate $(V \mathrm{~T} / t \mathrm{I})[6]$.

$P \mathrm{I}$ is increased if the elastic (stiff lungs, pulmonary oedema) or resistive (airways obstruction, asthma) load imposed on the inspiratory muscles is increased. Roussos et al. [8] directly related $P \mathrm{I} / P \mathrm{I}$, max with the time that the diaphragm can sustain the load imposed on it (endurance time). The critical value of $P \mathrm{I} / P \mathrm{I}$,max that could be generated indefinitely at functional residual capacity $(\mathrm{FRC})$ was $\sim 0.60$. Greater $P \mathrm{I} / P \mathrm{I}, \max$

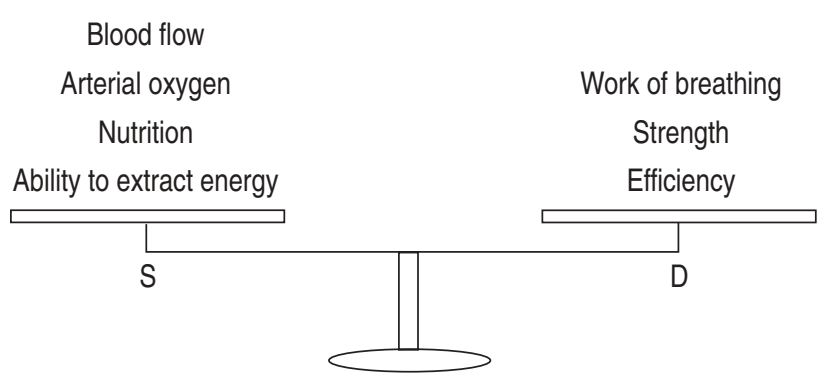

Fig. 3.-Respiratory muscle endurance is determined by the balance between energy supplies (S) and demands (D). Normally, the supplies meet the demands and a large reserve exists. Whenever this balance weighs in favour of demands, the respiratory muscles ultimately become fatigued, leading to inability to sustain spontaneous breathing. 
were inversely related to the endurance time. The critical value of $P \mathrm{I} / P \mathrm{I}$, max increases when end-expiratory lung volume increases. Indeed, when lung volume was increased from FRC to $\mathrm{FRC}$ plus $50 \%$ inspiratory capacity, the critical value of $P \mathrm{I} /$ $P \mathrm{I}$,max and the endurance time were diminished to very low values, 25-30\% PI,max. BELlEMARE and Grassino [9] also found that the maximum pressure that can be sustained indefinitely decreases when $t \mathrm{I} / t$ tot increases and suggested that the product of $P \mathrm{I} / P \mathrm{I}$,max and $t \mathrm{I} / t$ tot defined a useful "tension time index" that is related to the endurance time. Whenever the tension time index is below a critical value $(0.15$ for the diaphragm), the load can be sustained indefinitely.

A weak muscle requires more energy in relation to its maximum energy consumption to perform a given amount of work. The force developed by a skeletal muscle that is sufficient to produce fatigue is a function of the maximum force that the muscle can develop. Any condition that decreases the maximum force decreases the muscle's strength and predisposes to fatigue. Such conditions include atrophy (a probable result of prolonged mechanical ventilation), immaturity, neuromuscular diseases and performance in an inefficient part of the muscle's length/tension characteristics [10], as in a state of acute hyperinflation, during which both the diaphragm and intercostal muscles work at a shorter length.

Finally, muscle efficiency, the ratio of external work performed to energy consumed, is an important factor in energy demands. Inspiratory muscle efficiency is known to fall in patients with hyperinflation. It has been shown that, for the same work of breathing, the oxygen cost is markedly higher in patients with emphysema than in normal subjects [11]. This happens, in emphysematous patients, because either some inspiratory muscles may contract isometrically (they consume energy but do not perform work) or the inspiratory muscles are operating in an inefficient part of their force/length relationship: a more forceful contraction is required to produce a given pressure change, and an even greater degree of excitation is required to develop a given force. Thus both conditions lead to increased energy consumption for a given pressure development [12].

Factors determining the inspiratory muscle energy available are muscle blood flow, the $\mathrm{Ca}, \mathrm{O}_{2}$ and the blood substrate concentration as well as the ability of the muscles to extract energy (fig. 3).

Diaphragmatic blood flow is essentially determined by the perfusion pressure, which is a function of cardiac output and peripheral vascular resistance, and the vascular resistance of the muscle, which is a function of the intensity and duration of contraction [13]. As has been described in animal models, a reduction in cardiac output accompanying cardiogenic or septic shock is a cause of respiratory fatigue leading to severe alveolar hypoventilation, bradypnoea and respiratory arrest $[14,15]$. Energy supply to inspiratory muscles also depends on the ability of the muscle to increase blood flow in parallel with the increased work. The diaphragm has a greater capacity to increase blood flow than other skeletal muscles [16]. However, the amount that the inspiratory muscle blood flow can be increased may be affected by the intensity and duration of muscle contraction. If the respiratory muscles remain contracted throughout the respiratory cycle, as occurs in asthma [17], the overall blood flow to the muscles may be less than that required. In addition, haemoglobin concentration and oxyhaemoglobin saturation influence the aerobic energy supply to the muscle and hence its endurance.

Conditions characterised by inability of the muscles to extract and use energy, such as sepsis or cyanide poisoning, or diminished energy stores and glycogen depletion, as in extreme inanition, may potentially lead to respiratory muscle fatigue.

It is clear from the above discussion that fatigue may occur in a variety of clinical entities that alone or in combination result in an imbalance between respiratory muscle energy supplies and demands. No matter what the causes are, it is well known that fatigue is characterised by loss of force output [18], leading to inability of the respiratory muscles to develop adequate $P$ I during tidal breathing, with consequent decreases in $V \mathrm{~T}$ and $V^{\prime} \mathrm{E}$ and hypercapnia.

When the respiratory muscles are extensively loaded, however, it is likely that feedback mechanisms modify the central drive, which, by exerting "central wisdom", alters the ventilatory pattern and serves in reducing the load and alleviating fatigue, thus protecting the ventilatory pump from exhaustion, which, undoubtedly, is a terminal event.

Although there are no data from patients to substantiate the existence of "central wisdom" in ventilatory failure, there is enough evidence to support this notion. The fact that the reduction in $V \mathrm{~T}$ that followed resistive breathing in animals could be restored promptly to normal by administration of naloxone [19] or bilateral cervical vagotomy [20], as well as the fact that most hypercapnic patients with COPD can achieve normocapnia by voluntarily increasing their ventilation, implies that, although the subjects could increase their ventilation, they chose not to do so.

Indeed, alterations in the pattern of breathing may occur as a result of loading in animals [19], normal subjects [21] and patients during weaning trials [22].

Patients with acute and chronic respiratory failure as well as normal subjects and animals subjected to fatiguing respiratory loads tend to adopt rapid shallow breathing, consisting of a decrease in $V \mathrm{~T}$ and increased $f \mathrm{R}$, whereas $V^{\prime} \mathrm{E}$ remains constant or increases slightly. Although this pattern may not be efficient in terms of gas exchange, it may reduce the load on the muscle by decreasing the $P$ I developed, thereby preventing fatigue from occurring [23-26]. Moreover, in stable patients with COPD and carbon dioxide retention, this pattern of breathing may be sufficient to keep diaphragm contraction below the fatigue threshold [23, 27].

The neurophysiological mechanisms that cause an altered pattern of breathing are not well elucidated. Chemosensitivityinduced alterations in respiratory activity do not appear to be the explanation. Hypoxia- and hypercapnia-induced reductions in expiratory time $(\mathrm{E})$ are disproportionately greater than reductions in $t \mathrm{I}$, so that $t \mathrm{I} / t$ tot increases. Moreover, $V \mathrm{~T} / t \mathrm{I}$ and $V \mathrm{~T}$ increase rather than decrease [28].

Rapid shallow breathing may be produced by activation of vagal irritant receptors in the airways [29], or may represent a behavioural response to minimise the sense of dyspnoea [30].

Reflexes originating from mechanoreceptors in the contracting ribcage muscles and diaphragm (tendon organs, spindle organs, and type III and IV endings) probably play a role in shaping the rapid shallow pattern of breathing. In deeply anaesthetised animals, stretch of the intercostal muscles or increase in diaphragm tension may abruptly terminate inspiration [31]. Activation of endogenous opioid pathways has also been postulated to alter the pattern of breathing, perhaps as a mechanism by which the sense of dyspnoea might be reduced [19, 32-35].

Small-fibre afferents have been widely implicated in the response of central respiratory output to prolonged stresses such as shock, hypoxia, acidosis and vigorous exercise $[15,36$, 37]. It is possible that, during loaded breathing, afferents, through the small fibres, modulate endogenous opioids as an adaptive response to minimise breathlessness and avoid or delay the onset of respiratory muscle fatigue [38].

Whatever the mechanisms, however, the limit of this strategy is that with rapid shallow breathing $V^{\prime} \mathrm{ds} / V \mathrm{~T}$ is increased (see The respiratory equation section) with worsening of hypercapnia.

Although failure of the lungs leads mainly to hypoxaemia 
and failure of the ventilatory pump causes hypercapnia, it has to be emphasised that there are important interactions between these two entities. Furthermore, failure of one part (the lung) is often followed by failure of the second (ventilatory pump). Respiratory diseases that cause hypoxaemia are usually characterised by abnormal lung mechanics, a situation accompanied by increased work of breathing (resistive or elastic) and, therefore, energy demands. Taking into account the fact that the amount of energy available is reduced due to hypoxaemia, it is concluded that lung diseases may result in muscle fatigue and ventilatory failure through imbalance between demands and supplies.

Similarly, patients with diseases that involve the ventilatory pump (myopathies) and who present with hypercapnia are usually characterised by the inability to cough, which leads to accumulation of secretions and possibly atelectasis, a situation eventually aggravating ventilation/perfusion inequality with the result of hypoxaemia.

Pulmonary hyperinflation. In normal subjects at rest, the endexpiratory lung volume (FRC) corresponds to the relaxation volume $(V \mathrm{r})$ of the respiratory system, i.e. the lung volume at which the elastic recoil pressure of the total respiratory system is zero. Pulmonary hyperinflation is defined as an increase in FRC above the predicted normal value. This may be due to increased $V \mathrm{r}$ as a result of loss of elastic recoil of the lung (e.g. emphysema), or due to dynamic pulmonary hyperinflation, which occurs when FRC exceeds $V$ r [39].

Whatever its genesis, hyperinflation imposes several constraints on muscle function. For the inspiratory muscles, as for other skeletal muscles, there is an optimum length at which maximum force is developed. This length corresponds closely to FRC or to lower lung volumes [6]. With hyperinflation, the respiratory muscle fibres shorten, and thus the force available or the pressure developed for any given level of excitation is decreased. This results in a situation in which, for a given pressure swing necessary for adequate $V^{\prime} \mathrm{A}$, greater excitation, and thus a greater percentage of the available maximum pressure, is required. This increases the energy consumption for a given workload, and muscle efficiency is thus diminished.

The diaphragm is further compromised by the geometric distortion that hyperinflation induces in the inspiratory muscles. As the diaphragm is flattened and assumes a radius of infinity, Laplace's law $(P \mathrm{di}=2 T \mathrm{di} / \mathrm{Rdi}$, where $P$ di is transdiaphragmatic pressure, $T$ di the tangential tension generated by the diaphragm and Rdi the radius of curvature of the diaphragm) dictates that the diaphragm is no longer able to convert tension to pressure efficiently [40]. Apart from this, as the diaphragm flattens, the zone of opposition is reduced. This zone is the region of the costal diaphragm that abuts the lateral chest wall. In normal subjects, when the diaphragm contracts, the increase in abdominal pressure is transmitted to the ribcage through this zone, thereby facilitating thoracic expansion. Therefore, as lung volume increases, the contribution of diaphragmatic contraction to chest wall expansion is minimised.

Furthermore, hyperinflation alters the spatial orientation of diaphragmatic costal and crural fibres, forcing them to be arranged in series and perpendicularly with regard to the chest wall. During inspiration, contraction of these perpendicularly oriented fibres results in paradoxical inward movement of the lower ribcage (Hoover's sign).

As with the diaphragm, the length/tension characteristics and geometry of the thorax place the inspiratory intercostals or accessory muscles at a disadvantage during hyperinflation [6].

The work of breathing, almost invariably increased by the abnormal lung mechanics that lead to hyperinflation, is further increased by hyperinflation itself. Consequently, energy demands are increased, whereas energy supply may be limited due to sustained contraction of the respiratory muscles. The combination of increased work, decreased strength, decreased efficiency and decreased energy supply during hyperinflation puts the respiratory muscles at greater risk and makes them particularly prone to fatigue.

\section{Ventilatory failure in clinical conditions}

Hypercapnic respiratory failure may occur either acutely, insidiously or acutely upon chronic carbon dioxide retention.

\section{Hypercapnia of acute onset}

The pathological entities resulting in acute carbon dioxide retention are anatomical and functional defects of the CNS, impairment of neuromuscular transmission and mechanical defect of the ribcage, as well as conditions leading to fatigue of the respiratory muscles (table 1). Mechanisms responsible for carbon dioxide retention are both decreasing $V^{\prime} \mathrm{E}$ and increasing $V^{\prime} \mathrm{ds} / V \mathrm{~T}$.

Depression of the CNS due to pharmacological agents, infections or head trauma leads to hypoventilation due to impaired respiratory drive.

Mechanical defects of the chest wall (flail chest and acute hyperinflation), neuromuscular diseases (bilateral diaphragmatic paralysis, myasthenia Gravis, botulism and GuillainBarré syndrome) and pharmacological agents such as curare may result in acute hypercapnia.

Acute hypercapnia and eventually fatigue may occur in every clinical condition that is characterised by an increase in

Table 1.-Causes of alveolar hypoventilation, acute onset

\section{Decreased central drive}

Drugs (sedatives)

Central nervous system diseases (encephalitis, stroke, trauma)

Altered neural and neuromuscular transmission

Spinal cord trauma

Transverse myelitis

Tetanus

Amyotrophic lateral sclerosis

Poliomyelitis

Guillain-Barré syndrome

Myasthenia Gravis

Organophosphate poisoning

Botulism

Muscle abnormalities

Muscular dystrophy

Disuse atrophy

Prematurity

Chest wall and pleural abnormalities

Acute hyperinflation

Chest wall trauma (flail chest, diaphragmatic rupture)

Lung and airways diseases

Acute asthma

Acute exacerbation of chronic obstructive pulmonary disease

Cardiogenic and noncardiogenic pulmonary oedema

Pneumonia

Upper airways obstruction

Bronchiectasis

Other

Sepsis

Circulatory shock 
the mechanical load of breathing, and, consequently, in the energy demands that cannot be met by the energy supplies. Under these conditions, the CNS may reflexively adjust its outgoing signals in order to avoid complete depletion of vital chemicals within the muscle cell [18] and/or overt fatigue. In this way, $V \mathrm{~T}$ is reduced by diminishing $t \mathrm{I}$ in order for the $P \mathrm{I}$ to be diminished and therefore the energy demands per breath (tension time index per breath is reduced). In addition, with small tidal breaths, the respiratory muscles operate at a more optimal length that does not substantially affect their geometry. The reduction in $V \mathrm{~T}$ is compensated for, at least in the beginning, by increasing the $f \mathrm{R}$ so that $V^{\prime} \mathrm{E}$ is maintained or increased. Such a situation leads to rapid and shallow breathing [41, 42], increased $V^{\prime} \mathrm{ds} / V \mathrm{~T}$ and hypercapnia.

This $f \mathrm{R}$, however, is no longer optimal, and, for the same $V^{\prime} \mathrm{A}$, the energy demands are increased. Thus, although shortening of $t \mathrm{I}$ seems to be a better option in terms of energy demands, if coupled with high $f \mathrm{R}$ and possibly inadequate energy supply, as occurs during strenuous contractions, it may lead to muscle fatigue. Pressure generated by the inspiratory muscles then decreases with consequent decreases in $V \mathrm{~T}$ and $V^{\prime} \mathrm{E}$ and an increase in $V^{\prime} \mathrm{ds} / V \mathrm{~T}$ [42], with a subsequent reduction in $V^{\prime}$ A that is accompanied by an increase in $P \mathrm{a}, \mathrm{CO}_{2}$. At a later stage, $t \mathrm{I}$ increases again and the $f \mathrm{R}$ gradually decreases, resulting in a further drop in $V^{\prime} E$ [43]. In extreme fatigue, the CNS reduces the output signals per breath, leading to respiratory arrest [14].

Thus alveolar hypoventilation with consequent hypercapnia is the result of a reduced tension time index, which may be due to muscle fatigue or possibly adaptation of the CNS before the development of overt fatigue.

In an acute asthmatic attack, characterised by severe airways obstruction, the rapid shallow breathing associated with the increased elastic and resistive inspiratory load increases the work of breathing and consequently the energy demands. Reduced strength and efficiency of the respiratory muscles due to hyperinflation, as well as impaired blood supply to them due to strong muscle contractions, probably leads to decreased $P \mathrm{I}, \mathrm{max}$, while, at the same time, $P \mathrm{I}$ is increased. Increased $P \mathrm{I} / P \mathrm{I}, \max$ leads to dyspnoea [30], and, potentially, if a critical value is crossed, fatigue. Such a situation forces alveolar hypoventilation by reducing $V \mathrm{~T}$, either as a protective mechanism for the muscles, since there is enough evidence that strenuous breathing causes muscle injury $[44,45]$, or as a consequence of fatigue of the muscles.

In noncardiogenic (ARDS) and cardiogenic pulmonary oedema, energy demands are increased due to increased elastic work and hyperventilation, whereas energy supply is diminished due to hypoxaemia in the former, and hypoxaemia as well as low cardiac output in the latter. In such situations, the respiratory muscles may fail.

Acute hypercapnic respiratory failure may also develop in patients with acute respiratory failure receiving mechanical ventilation during the weaning trial. The pathophysiological pathways that lead to carbon dioxide retention have been better studied in this group of patients, since, in other clinical conditions, it is difficult, if not unethical, to delay therapeutic interventions in order to document the physiological parameters.

In the first relevant and very significant study, performed by COHEN et al. [43], it was noticed that the majority of patients who failed the weaning trial presented with tachypnoea, acidosis and fatigue of the respiratory muscles. The above authors, as well as others subsequently, proposed that fatigue may be the final common pathway leading to hypercapnic respiratory failure during discontinuation from mechanical ventilation [22]. Further research regarding this issue has shown that rapid shallow breathing (with the consequent rise in $\left.V^{\prime} \mathrm{ds} / V \mathrm{~T}\right)$, as well as a significant increase in the elastic and resistive load of the respiratory muscles, are the major causes of carbon dioxide retention in these patients $[22,24]$. Although there is some controversy regarding the exact role of inspiratory muscle fatigue during weaning failure, there are enough data offering significant support in favour of fatigue. GOLDSTONE et al. [46], upon measuring maximum relaxation rate during weaning, observed a decline in those patients failing to be weaned, a finding suggesting that a fatigue process is initiated peripherally in the respiratory muscles. Furthermore, using criteria similar to COHEN et al. [43], BROCHARD et al. [47] found that patients who failed to be weaned exhibited electromyographic signs of fatigue during spontaneous breathing followed by a decrease in $V \mathrm{~T}$, increase in $f \mathrm{R}$ and development of hypercapnia. Disuse atrophy of the respiratory muscles, a well documented condition after short- and long-term mechanical ventilation [48], malnutrition, the decreased perfusion that is often seen in these patients, and also decreased strength and efficiency of the muscles due to hyperinflation are conditions that decrease respiratory muscle capacity. These, coupled with increased mechanical load, are situations leading to respiratory muscle fatigue.

The fact that the weaning trial was interrupted and ventilatory support resumed prior to inspiratory muscle exhaustion once the patients presented with clinical signs of respiratory distress (in the period of time before the appearance of muscle fatigue) may explain why some investigators failed to document long-lasting diaphragmatic fatigue in patients failing to be weaned from the ventilator [49]. Furthermore, it should be emphasised that fatigue is not an "all or nothing phenomenon" [50]; rather the impairment in contractility is more likely to exist in the form of a continuum.

In most neuromuscular diseases with acute onset (e.g. diaphragmatic paralysis or the effects of poisons such as organophosphates), weakness of the respiratory muscles is a very common feature, and leads to ventilatory failure. Weakness could also be the result of muscle atrophy, malnutrition, electrolytic disorders or immature respiratory muscles, as in newborn babies. In these situations, the remaining normal muscle cells cannot develop sufficient force to maintain adequate $V^{\prime} \mathrm{A}$, and they eventually become fatigued.

\section{Insidious onset of hypercapnia}

Patients with chronic hypercapnia have to breathe against increased forces imposed by either the lung (as in bronchitis and emphysema) or chest wall (as in kyphoscoliosis, extreme obesity or neuromuscular disorders), or both (as in scleroderma and polymyositis) (table 2).

Although chronic hypercapnia is most frequently seen in COPD, where it is associated with an ominous prognosis [51], the mechanisms leading to its occurrence are not completely understood. The relationship of $\mathrm{Pa}, \mathrm{CO}_{2}$ with indices of airways obstruction or ventilation/perfusion mismatch is weak [52], suggesting that factors other than lung pathology may be operative.

More than half a century ago, two hypotheses were proposed in order to explain chronic hypercapnia in these patients. SCOTT [53], in 1920, suggested that impaired ventilation is the result of chemical factors that influence the respiratory drive through changes in the chemical environment of the respiratory centres. CHRISTIE [54], in 1934, proposed that ventilatory insufficiency is primarily the result of abnormal respiratory mechanics, and that the respiratory muscles are unable to perform the necessary work to provide adequate ventilation and hence carbon dioxide levels rise. The fact that most hypercapnic COPD patients can achieve 
Table 2. - Causes of alveolar hypoventilation, insidious onset

\section{Lung and airways diseases}

Chronic obstructive airway disease (bronchitis, emphysema, bronchiectasis)

Chest wall abnormalities

Kyphoscoliosis

Thoracoplasty

Obesity

Pleural effusion

Neuromuscular disorders

Lung and chest wall diseases

Scleroderma

Polymyositis

Systemic lupus

Central nervous system abnormalities

Primary alveolar hypoventilation (Ondine's curse)

Other

Electrolyte abnormalities

Malnutrition

Endocrine disorders

normocapnia by voluntarily increasing their ventilation [55] makes the two hypotheses above untenable. Given the increase in $V^{\prime} \mathrm{ds} / V \mathrm{~T}$ ratio that occurs in $\mathrm{COPD}, P \mathrm{a}, \mathrm{CO}_{2}$ could be maintained at or near normal levels provided that $V^{\prime} \mathrm{E}$ can be preserved at a sufficiently high level. The fact that, in steadystate COPD patients, deep breathing brings the respiratory muscles near to fatigue and cannot be tolerated for more than a few minutes [27] probably indicates that hypercapnic COPD patients choose to act as "wise fighters", who, instead of increasing their ventilation (an option that could potentially lead to muscle fatigue), choose to hypoventilate.

The problem with maintaining $V^{\prime} \mathrm{E}$ above normal levels is that this is associated with significant mechanical impediments to breathing. Since COPD patients are characterised by increased airflow resistance and reduced dynamic compliance, the resistive and elastic loads are increased and hence the inspiratory muscles have to generate higher forces to inflate the lung. The emphysematous changes in the lung cause hyperinflation, which forces the inspiratory muscles to operate at shorter than normal lengths and reduces their ability to lower the intrathoracic pressure. More importantly, the dynamic hyperinflation that develops in these patients due to limitation of expiratory flow imposes a severe strain on the respiratory muscles because of the additional load that is placed on them (intrinsic positive end-expiratory pressure (PEEPi)) and because of impairment of their operating length and geometry.

Subsequently, the balance between the mechanical impediments to breathing and the capacity of the inspiratory muscles to cope with them, expressed by $P \mathrm{I} / P \mathrm{I}, \max$, is shifted in an unfavourable direction (more work/less muscle reserve). Under such conditions, COPD patients choose to reduce $P$ I by reducing $V \mathrm{~T}$. A reduced $V \mathrm{~T}$ may reflect reduced central respiratory drive, or, alternatively, mechanical limitation and/ or inspiratory muscle dysfunction.

A subnormal respiratory output has long been postulated as a mechanism of hypercapnia in patients with COPD. However, neural drive assessed by mouth occlusion pressure has been found to be higher in COPD patients than in normal subjects [56], although no significant differences were found between normocapnic and hypercapnic patients. In addition, neural drive assessed by surface electromyographic activity of the diaphragm was also found to be increased in both normocapnic and hypercapnic COPD patients [57]. Furthermore, the voluntary drive to breathe has been shown not to be decreased in hypercapnic COPD patients [58]. Consequently, although, in these patients, the respiratory drive to breathe is increased, they are better off shortening the $t \mathrm{I}$, a process that results in a lower $V \mathrm{~T}$.

The reduction in $V \mathrm{~T}$ is largely offset by an increase in the $f \mathrm{R}$, such that $V^{\prime} \mathrm{E}$ is well preserved. However, rapid shallow breathing has undesirable consequences. The increased $f \mathrm{R}$ aggravates dynamic hyperinflation and increases $V^{\prime} \mathrm{ds} / V \mathrm{~T}$. The pattern of breathing in COPD patients has been examined in several studies. Comparing normal persons with hypercapnic and normocapnic stable COPD patients, SORLI et al. [56] noted that hypercapnic patients breathed faster and more shallowly than either normal persons or normocapnic subjects and so, at equal $V^{\prime} \mathrm{E}, V^{\prime} \mathrm{ds} / V \mathrm{~T}$ was higher in the carbon dioxide retainers. Decreased $V \mathrm{~T}$ and increased $V^{\prime} \mathrm{ds} / V \mathrm{~T}$ were also found by BEGIN and GRASSINO [59] in severely hypercapnic COPD patients. The authors suggested that chronic alveolar hypoventilation is likely to develop in COPD patients who have a combination of high inspiratory loads (resistive and elastic) and greater hyperinflation, factors that effectively reduce $P I$, max, thus increasing the fraction of force developed/ force available for breathing (less efficient muscles). These data were confirmed by GORINI et al. [60], who found that $V \mathrm{~T}$ was related directly to $t \mathrm{I}$, indicating that a small $V \mathrm{~T}$ was primarily the consequence of alterations in respiratory timing.

The mechanisms leading to alterations in respiratory timing in patients with COPD have not yet been clearly defined. Changes in the pattern of breathing may represent a behavioral response in order to minimise the sense of dyspnoea. The sense of dyspnoea is a complex perceptual construct, probably multifactorial [30]. Studies indicate that the sense of breathlessness increases with increases in the intrathoracic pressure required to maintain airflow and $V \mathrm{~T}, t \mathrm{I}$ (relative to $t$ tot) and $f \mathrm{R}$. Thus, at a given $V^{\prime} \mathrm{E}$ and set of respiratory mechanics, the pattern of breathing determines the intensity of breathlessness.

In the study of BEGIN and GRASSINO [59], in the COPD patients who presented with gross hyperinflation (residual volume/total lung capacity $76 \%$ ) and hypercapnia, $P \mathrm{I} / P \mathrm{I}$, max was markedly increased compared to normal subjects (27 versus $10 \%$ ), a value highly probable to predispose the muscles to fatigue [4]. Thus it could be suggested that, as the disease progresses, the critical level of power output for muscle fatigue is exceeded in order to permit the patient to maintain adequate $V^{\prime}$ A. Thus it seems evident that, when the muscles become unable to develop enough force, the activation system comes into play and may alter the pattern of breathing in an attempt to optimise the performance of the muscles and possibly postpone or prevent severe fatigue.

Although the underling mechanisms are not known, it is speculated that afferents from the small fibres stimulated by the heavy work (ergoreceptors, type III) or noxious substances (nociceptors, type IV) modify CNS output.

\section{Acute-on-chronic respiratory failure}

Acute deterioration in a patient with chronic respiratory failure is termed acute-on-chronic respiratory failure. Patients may present with worsening dyspnoea, deteriorating mental status or respiratory arrest after relatively minor, although often multiple, insults. Acute-on-chronic respiratory failure is usually seen in patients known to have severe COPD. Patients with severe but stable COPD exist in a very critical balance between increased demands and limited reserves. Any factor that potentially interferes with this balance (either increase in demands or decrease in reserves) leads to respiratory muscle fatigue and acute respiratory failure. 
Patients with COPD experience an increased respiratory system load due to abnormal airway resistance and respiratory system elastance. The increased resistance is caused by bronchospasm, airway inflammation or physical obstruction by mucus and scarring. The most significant contributor to the elastic load is dynamic hyperinflation that develops whenever the $t \mathrm{E}$ is insufficient to allow the lungs to deflate to $\mathrm{Vr}$ prior to the next inspiration. This tends to occur under conditions in which expiratory flow is impeded (increased airway resistance) or when the $t \mathrm{E}$ is shortened (increased $f \mathrm{R}$ ) $[39,61]$. Expiratory flow may also be retarded by other mechanisms such as persistent constriction of the respiratory muscles during expiration. Most commonly, however, dynamic pulmonary hyperinflation is observed in COPD patients who exhibit expiratory flow limitation during resting breathing and plays a paramount role in causing respiratory failure.

When breathing takes place at lung volumes greater than $V \mathrm{r}$, a positive elastic recoil pressure called PEEPi remains at end-expiration.

When PEEPi is present, the inspiratory muscles have to generate greater effort to overcome an equal amount of pressure before airflow starts. In this respect, PEEPi acts as an inspiratory threshold load which increases the static elastic work of breathing. On average, it has been found that the inspiratory work due to PEEPi represents $57 \%$ of the overall increase in the work of breathing exhibited by COPD patients relative to normal subjects [62].

Owing to hyperinflation, tidal breathing occurs at a steeper portion of the pressure/volume curve of the lung (increased elastance), increasing the inspiratory load. Apart from increasing elastic loads, dynamic hyperinflation is accompanied by a concomitant decrease in the effectiveness of the inspiratory muscles as pressure generators, because the inspiratory muscle fibres become shorter and their geometric arrangement changes (see Pulmonary hyperinflation section). However, patients presenting with acute-on-chronic respiratory failure may show not only worsening hyperinflation but also other conditions that cause muscle weakness (protein/ calorie malnutrition and steroid myopathy). Figure 4 shows a schematic representation of the sequence of responsible mechanisms that lead to acute-on-chronic respiratory failure in COPD patients.

Acute ventilatory failure in these patients is usually triggered by airway infection. The increased $f \mathrm{R}$, which is invariably present in acutely ill COPD patients [39,63] due to shortened $t \mathrm{E}$, further exacerbates dynamic hyperinflation, which promotes an increase in the static elastic work of breathing (due to both PEEPi and decreased lung compliance). At the same time, an acute increase in airway resistance (bronchoconstriction and copious secretions) causes an increase in the resistive work of breathing. The increased work of breathing associated with this impaired muscle effectiveness leads to an increase in energy requirements, which, at a critical point, exceeds the diminished energy available (hypoxaemia and impaired diaphragmatic blood flow due to forceful contractions) and respiratory muscle fatigue ensues with a further increase in $\mathrm{Pa}, \mathrm{CO}_{2}$.

\section{Perspectives: hypothalamic-pituitary-adrenal axis and ventilatory failure}

Although the processes leading to acute hypercapnic respiratory failure have been thoroughly elucidated, the pathophysiological mechanisms responsible for chronic carbon dioxide retention are not yet clear. The fact that patients with COPD who most probably could increase their ventilation [55] choose not to and as a result develop chronic hypercapnia

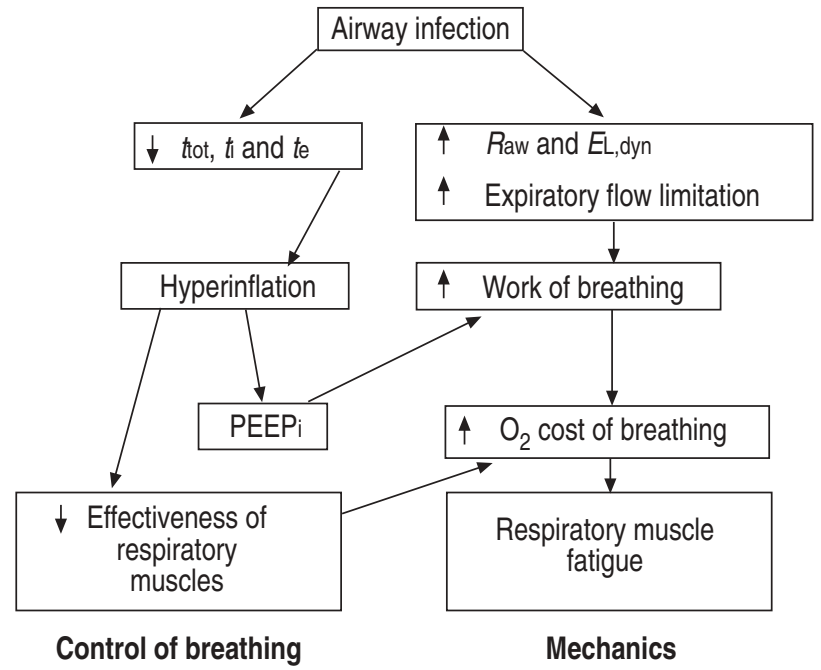

Fig. 4.-Schematic representation of the sequence of responsible mechanisms that lead to acute-on-chronic respiratory failure in patients with chronic obstructive pulmonary disease. $t$ tot: total respiratory cycle; $t \mathrm{I}$ : inspiratory time; te: expiratory time; Raw: airway resistance; EL,dyn: dynamic elastance of the lung; PEEPi: intrinsic positive end-expiratory pressure; $\downarrow$ : decrease; $\uparrow:$ increase.

permits the speculation that it might be "natural wisdom" that protects these patients from the disastrous consequences of their disease, but with the inevitable cost of hypercapnia.

The study and eventually the partial elucidation of the multiplicity of mechanisms functioning through "natural wisdom" would probably be an interesting and satisfying experience for the investigator in this field.

Since the intense strain of the diaphragm that is usually required for adequate $V^{\prime} \mathrm{A}$ under conditions of increased load and/or reduced efficiency has been proven to lead to structural damage of the respiratory muscles [44, 45], it could be assumed that a protective mechanism might exist in order to protect the respiratory muscles from damage.

Although no indisputable evidence exists to prove the mechanisms involved in chronic carbon dioxide retention, there are sufficient data to permit speculation concerning the way in which peripheral mechanical or chemical stimuli are transferred and modify the pattern of breathing [36, 37].

Until the early 1970 s, the respiratory central nervous discharge had been considered to be affected predominantly by central and peripheral chemoreceptors and vagal afferents, and to a lesser extent by muscular afferents, with a role that seemed of minor importance. The effects of sensory information traveling via the phrenic nerves on the central respiratory centres were not very well elucidated, although it was known that nonmyelinated fibres constituted a large proportion of the entire phrenic nerve $[64,65]$. The functional existence of small myelinated and nonmyelinated phrenic afferent fibres (types III and IV respectively), as well as their influence on central inspiratory neural activity, was confirmed in anaesthetised cats, in which it was shown that selective stimulation of these fibres influences the respiratory rhythm (altering the $t \mathrm{I} / t$ tot) and hence central inspiratory activity [36]. Under states of severe thoracic stress (muscle tension, local ischaemia and accumulation of toxic metabolites), afferents from the respiratory muscles may play a predominant role in the genesis of the particular breathing pattern. As has been shown, the characteristic response to breathing against a fatiguing load or in a state of reduced respiratory blood flow is tachypnoea, initially followed by bradypnoea and respiratory arrest [14, 37]. Since this response is not affected in animals, by either vagotomy, eliminating vagal afferents, or cross-perfusion of 
the head, eliminating chemoreceptor afferents, it seems reasonable to suggest that afferent information from type III and IV receptors would potentially increase their effect on the central respiratory controllers and alter ventilatory timing [36, 37].

The influence of afferent phrenic fibres on breathing pattern, as well as possible stimuli triggering them, has been studied in anaesthetised animals during eupnoea or fatigue trials $[38,66]$. In conscious goats, strenuous resistive breathing was associated with a biphasic electromyographic response in the diaphragm [67], consisting of an initial and immediate increase (facilitation) followed by a partial decrease (inhibition). Both responses have been attributed to small afferent fibre activation, initially causing facilitation, and, in a timeand/or intensity-dependent manner, partial inhibition through the elaboration of $\beta$-endorphin. A direct link between stimulation of group III and IV afferents and the central elaboration of endogenous opioids has also been suggested by KumAzAwA et al. [68], who showed that, in anaesthetised dogs, respiratory depression persisted even after withdrawal of afferent fibre stimulation, whereas the magnitude of the respiratory depression was significantly reduced by naloxone. Other investigators have confirmed these results in cats and demonstrated that the phenomenon involved a supraspinal mechanism [69] which could be prevented by pretreatment with naloxone [32], thus strongly indicating involvement of endogenous opioid pathways.

The role of exogenous or endogenously generated opioids as neurotransmitters or neuromodulators of a complex inhibitory system of respiration has been extensively studied. When injected into the cisternal cerebrospinal fluid, heroin caused a reduction in $V \mathrm{~T}$ [33], indicating a direct inhibitory effect of this opioid on respiration. In COPD patients whose respiratory responses to flow resistive loading were absent, the responses could be immediately restored by administration of naloxone [34], suggesting that the chronic increase in airway resistance in these patients generated endogenous opioids as an adaptive response, which served to lessen the stress of prolonged dyspnoea. Acute short-term inspiratory resistive loading resulted in a reduction in $V \mathrm{~T}$ and mean inspiratory flow rate in unanaesthetised goats, as well as an increase in the levels of cisternal cerebrospinal fluid imunoreactive $\beta$-endorphin [19]. Both $V \mathrm{~T}$ and mean inspiratory flow rate could be transiently increased by naloxone administration, demonstrating that a proportion of these effects could have been meditated by elaboration of endogenous opioids. These data imply that endogenous opioids caused a progressive decline in the discharge rate of the respiratory centres that allow a reduction in inspiratory activity per breath in order to minimise the work of the respiratory muscles, since a reduced $V \mathrm{~T}$ requires less pressure development, and delay or prevent the onset of overt muscle fatigue.

Although strenuous inspiratory resistive breathing has been found to produce $\beta$-endorphin not only in animals but also in humans $[35,70]$, the source of these substances remains elusive, and both central sites such as the hypothalamicpituitary-adrenal axis and peripheral sites such as the spinal cord and peripheral nerves have been implicated [67].

Recently, it was shown that, in normal human volunteers, strenuous resistive breathing leads to a significant rise in the levels of the pro-inflammatory cytokines interleukin (IL)- $1 \beta$, IL- 6, adrenocorticotropic hormone (ACTH) and $\beta$-endorphin [71]. The strong relationships between the rise in $\beta$-endorphin and ACTH levels and the preceding increase in circulating IL-6 levels allowed the authors to suggest that pro-inflammatory cytokines, and especially IL-6, are responsible for activation of the hypothalamic-pituitary-adrenal axis, leading eventually to an increase in plasma $\beta$-endorphin and ACTH levels, given that both are derived from post-translational modification of the same molecule, pro-opiomelanocortin [72], and are concomitantly secreted by the pituitary gland [73, 74]. It is tempting to suggest that the mechanism accounting for the increase in $\beta$-endorphin and ACTH levels could be the stimulation of small afferent nerve fibres by the cytokines that are produced during resistive breathing (fig. 5). Indeed, global depletion of small afferent fibres inhibits the plasma ACTH response to intravenous IL-1 $\beta$ [75].

Although the stimuli for the production of the cytokines are not known, reactive oxygen species produced within the respiratory muscles during fatiguing resistive breathing [76, 77] could probably be responsible. It has very recently been discovered that antioxidant administration in healthy volunteers significantly blunts the strenuous resistive breathinginduced cytokine response [78]: the tumour necrosis factor- $\alpha$ response was abolished, IL-1 $\beta$ became undetectable, and the IL-6 response was blunted. Thus it is possible that plasma cytokine induction during resistive breathing is differentially regulated by various stimuli, some of them being common (reactive oxygen species), whose relative importance varies with each respective cytokine.

Even though the present authors acknowledge that the time profile (brief) and intensity (much greater) of the increased resistance in the above mentioned models are different from those in patients with chronic carbon dioxide retention, given that strenuous breathing causes diaphragm muscle fibre injury consisting of membrane damage, sarcomere disruption [44, 45] and lactic acid production [38], the following hypothesis could be arrived at (fig. 6). Strenuous resistive breathing, through reactive oxygen species, induces plasma cytokine production, especially IL-6, which in turn modulates the respiratory controllers either directly through the blood or probably the small afferents or via the hypothalamic-pituitaryadrenal axis. The ensuing stimulation of the hypothalamicpituitary-adrenal axis by the cytokines might have a dual purpose: the ACTH response may represent an attempt of the organism to reduce the injury occurring in the respiratory muscles through the production of glucocorticoids by the adrenals [79]. At the same time, production of $\beta$-endorphin decreases the activation of the respiratory muscles [35] and alters the pattern of breathing [19] in an attempt to reduce and/or prevent further injury at the cost of $V^{\prime} \mathrm{A}$.

\section{Conclusions}

The respiratory system consists essentially of two parts: a gas exchanging organ, the lungs, and a pump that ventilates the lungs. The pump consists of the chest wall, the respiratory muscles that displace the chest wall, the respiratory centres of the CNS that control the muscles and the nerves connecting the centres to the muscles. Both parts of the system are vital. In general, failure of the gas exchanging function due to lung disease (i.e. ARDS, pneumonia and pulmonary emboli) results mainly in hypoxaemia with normocapnia or hypocapnia (type I respiratory failure). Failure of the pump (i.e. CNS depression, weakness and trauma), which also causes hypoxaemia, leads to hypoventilation and hypercapnia which is the hallmark of ventilatory failure (type II respiratory failure).

Hypercapnic respiratory failure may occur either acutely, insidiously or acutely upon chronic carbon dioxide retention. In all these conditions, pathophysiologically, the common denominator is reduced $V^{\prime} \mathrm{A}$ for a given $V^{\prime} \mathrm{CO}_{2}$.

Mechanical disorders are often a cause of alveolar hypoventilation. Disorders with hypoventilation can easily be seen in chest wall trauma (flail chest), excessive hyperinflation (in hyperinflated patients with obstructive lung disease) and kyphoscoliosis. Neuromuscular disorders in which the patients 

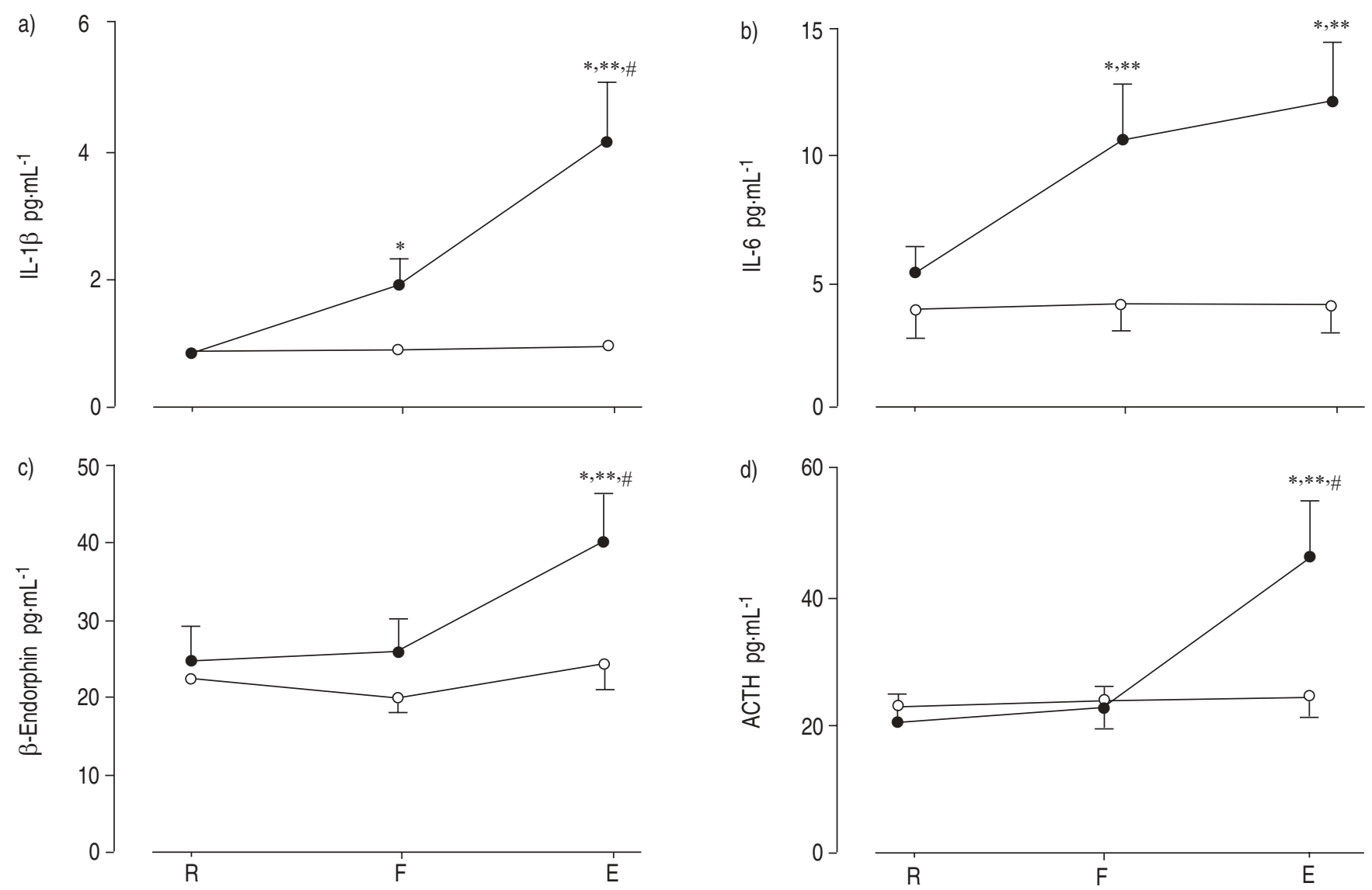

Fig. 5. - Mean plasma levels of: a) interleukin (IL)-1 $\beta$; b) IL-6; c) $\beta$-endorphin; and d) adrenocorticotropic hormone (ACTH) at rest (R), the point at which subjects could not generate the target maximum inspiratory pressure $(\mathrm{F})$ and the end of resistive breathing (E) (@: high load; $\bigcirc$ : moderate load). Data are presented as mean \pm SEM. *: $\mathrm{p}<0.05$ versus $\mathrm{R}$; ${ }^{\#}: \mathrm{p}<0.05$ versus $\mathrm{F}$; **: $\mathrm{p}<0.01$ versus moderate load. (Reproduced with permission from [66]).

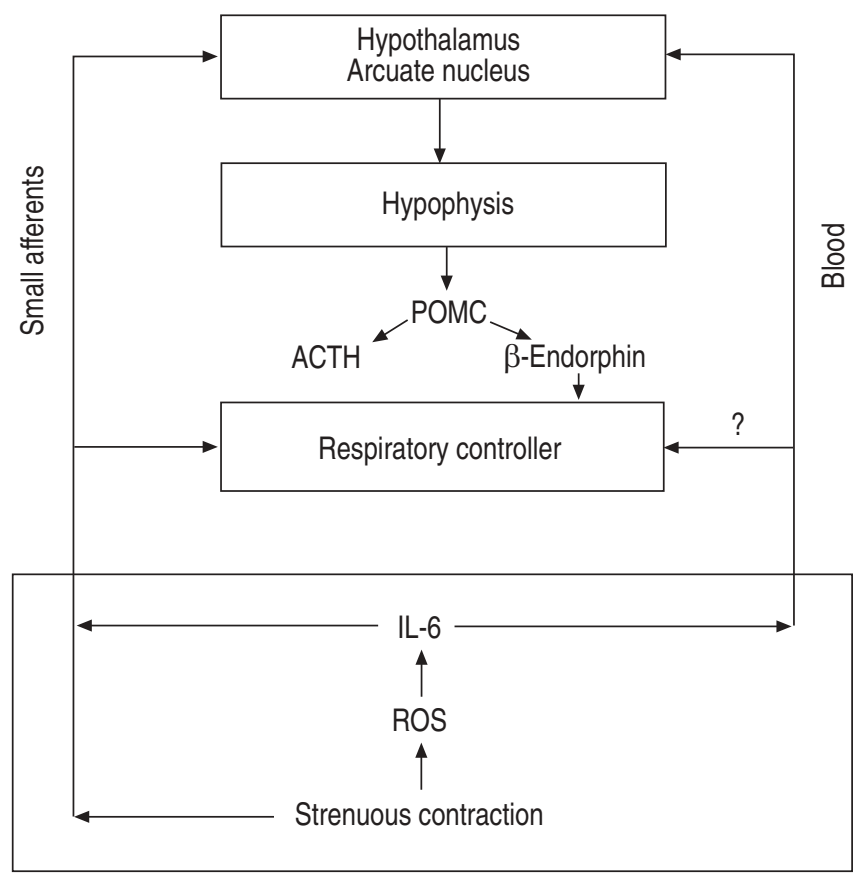

Respiratory muscles

Fig. 6. - Possible loop between respiratory muscles and central controllers: reactive oxygen species (ROS), interleukin (IL)-6, small fibres, hypothalamic-pituitary-adrenal axis, adrenocorticotropic hormone $(\mathrm{ACTH})$ and endorphins. POMC: pro-opiomelanocortin. present with a weakness, as, for example, in overdose, CNS lesions and neuromuscular diseases, lead to alveolar hypoventilation either acutely or chronically. Imbalance of energy demand and supply may eventually lead to respiratory muscle fatigue (i.e. shock), and, in turn, to reduced ventilation resulting in hypercapnia.

Extensive discussion over many years has not provided an answer as to why some patients develop chronic hypercapnia as in chronic obstructive pulmonary disease, kyphoscoliosis and neuromyopathies. The most attractive hypothesis in this disorder is the theory of "natural wisdom". Patients facing a load have two options: either to push hard in order to maintain normal arterial oxygen and carbon dioxide tensions at the cost of eventually becoming fatigued and exhausted or breathe at a lower minute ventilation, avoiding dyspnoea, fatigue and exhaustion but at the expense of reduced alveolar ventilation. Credence is lent to this latter option, which the present authors favour, by most recent work. In brief, it is possible that a threshold inspiratory load may exist, which, whenever exceeded, results in injury to the muscles, and, consequently, an adaptive cytokine and hormonal response is elicited to prevent and/or reduce the damage. This, however, culminates in alveolar hypoventilation and carbon dioxide retention.

\section{References}

1. Roussos C. Ventilatory failure and respiratory muscles. In: Roussos C, Macklem PT, eds. The Thorax. New York, NY, Marcel Dekker, 1985; pp. 884-888. 
2. Hall JB, Schmidt GA, Wood LD. Acute hypoxemic respiratory failure. In: Murray JF, Nadel JA, eds. Textbook of Respiratory Medicine. Philadelphia, PA, Saunders, 2000; pp. 2413-2442.

3. Roussos C. The failing ventilatory pump. Lung 1985; 160: 59-84.

4. Roussos C. Function and fatigue of respiratory muscles. Chest 1985; 88: 124S-132S.

5. Macklem PT. Respiratory muscles: the vital pump. Chest 1980; 78: 753-758.

6. Roussos C, Macklem PR. The respiratory muscles. $N$ Engl J Med 1982; 307: 786-797.

7. Vasilakopoulos T, Zakynthinos S, Roussos C. Respiratory muscles and weaning failure. Eur Respir $J$ 1996; 9: 2383-2400.

8. Roussos C, Fixley D, Gross D, Macklem PT. Fatigue of the respiratory muscles and their synergistic behavior. $J$ Appl Physiol 1979; 46: 897-904.

9. Bellemare F, Grassino A. Effects of pressure and timing of contraction on human diaphragm fatigue. J Appl Physiol 1982; 53: 1190-1195.

10. Farkas G, Roussos C. Acute diaphragmatic shortening: in vitro mechanics and fatigue. Am Rev Respir Dis 1984; 130: 434-438.

11. McGregor M, Beklake MR. The relationship of oxygen cost of breathing to respiratory mechanical work and respiratory force. J Clin Invest 1961; 40: 971-980.

12. Macklem PT, Gross D, Grassino A, Roussos C. Partitioning of the inspiratory pressure swings between diaphragm and intercostal/accessory muscles. J Appl Physiol 1978; 44: 200-208.

13. Humphreys PS, Lind AR. Blood flow through active and inactive muscle of the forearm during isolated hand grip contractions. J Physiol (Lond) 1963; 166: 120-135.

14. Aubier M, Trippenbach T, Roussos C. Respiratory muscle fatigue during cardiogenic shock. J Appl Physiol 1981; 51: 449-508.

15. Hussain SNA, Simkus G, Roussos C. Respiratory muscle fatigue: a cause of ventilatory failure in septic shock. $J$ Appl Physiol 1985; 58: 2033-2040.

16. Robertson CH, Eschenbacher JW, Johnson RL. Respiratory muscle blood flow distribution during expiratory resistance. $J$ Clin Invest 1977; 60: 473-480.

17. Muller N, Bryan A, Zamel N. Tonic inspiratory muscle activity as a cause of hyperinflation in histamine-induced asthma. J Appl Physiol 1980; 49: 869-874.

18. Roussos C, Moxham J, Bellemare F. Respiratory muscle fatigue. In: Roussos C, ed. The Thorax. New York, NY, Marcel Dekker, 1995; pp. 1405-1461.

19. Scardella AT, Parisi RA, Phair DK, Santiago TV, Edelman NA. The role of endogenous opioids in the ventilatory response to acute flow-resistive loads. Am Rev Respir Dis 1986; 133: 26-31.

20. Adams JM, Farkas GA, Rochester DF. Vagal afferents, diaphragm fatigue and inspiratory resistance in the anesthetized dog. J Appl Physiol 1988; 64: 2279-2286.

21. Tobin M, Perez W, Guenther S, Lodato RF, Dantzker DR. Does rib-cage abdominal paradox signify respiratory muscle fatigue? J Appl Physiol 1987; 63: 851-860.

22. Zakynthinos S, Vasilakopoulos T, Roussos C. The load of inspiratory muscles in patients needing mechanical ventilation. Am J Respir Crit Care Med 1995; 152: 1248-1255.

23. Roussos C. Ventilatory muscle fatigue governs breathing frequency. Bull Eur Physiopathol Respir 1984; 20: 445-451.

24. Tobin MJ, Perez W, Guenther SM, Semmes BJ. The pattern of breathing during successful and unsuccessful trials of weaning from mechanical ventilation. Am Rev Respir Dis 1986; 143: 1111-1118.

25. Milic-Emili J. Is weaning an art or a science? Am Rev Respir Dis 1986; 134: 1107-1108.

26. Bellemare F. Respiratory muscle function. In: Kelley WN, ed. Textbook of Internal Medicine. Philadelphia, PA, JP Lippincott 1989; pp. 1843-1891.

27. Bellemare F, Grassino A. Force reserve of the diaphragm in patients with chronic obstructive pulmonary disease. $J$ Appl Physiol 1983; 55: 8-15.

28. Kelsen SG, Jammes Y, Cherniack NS. Control of motor activity to the respiratory muscles. Thorax 1985; 16: 493-529.

29. Coleridge HM, Coleridge JCG. Reflexes evoked from tracheobronchial tree and lungs. In: Cherniac NS, Widdicombe JG, eds. Handbook of Physiology. Section 3. The Respiratory System Vol. II. Control of Breathing. Part 1. Bethesda, MD, American Physiological Society, 1986; pp. 395-429.

30. Killian KJ, Summers E, Basalygo M, Campbell EJ. Effect of frequency on perceived magnitude of added loads to breathing. J Appl Physiol 1985; 58: 1616-1621.

31. Shannon R. Reflexes from respiratory muscle and costovertebral joints. In: Cherniac NS, Widdicombe JG, eds. Handbook of Physiology. Section 3. The Respiratory System Vol. II. Control of Breathing. Part 1. Bethesda, MD, American Physiological Society, 1986; pp. 431-447.

32. Waldrop TG, Eldridge FL, Milhorn DE. Inhibition of breathing after stimulation of muscle is mediated by endogenous opiates and GABA. Respir Physiol 1983; 54: 211-222.

33. Taveira DaSilva AM, Souza JD, Quest JA, et al. Central nervous system site of action for the respiratory depressant effect of diacetylmorphine (heroin) in the cat. J Clin Invest 1983; 72: 1209-1217.

34. Santiago TV, Remolina C, Scoles Veldeman NH. Endorphins and the control of breathing: ability of naloxone to restore flow-resistive load compensation in chronic obstructive pulmonary disease. N Engl J Med 1981; 304: 1190-1195.

35. Santiago TV, Edelman NH. Opioid and breathing. $J$ Appl Physiol 1985; 59: 1675-1685.

36. Jammes Y, Buchler B, Delpierre S, Rasidakis A, Grimaud C, Roussos C. Phrenic afferents and their role in inspiratory control. J Appl Physiol 1986; 60: 854-860.

37. Hussain SNA, Magder S, Chatillon A, Roussos C. Chemical activation of thin fiber phrenic afferents: respiratory responses. J Appl Physiol 1990; 69: 1002-1011.

38. Petrozzino JJ, Scardella AT, Santiago TV, Edelman NH. Dichloroacetate blocks endogenous opioid effects during inspiratory flow-resistive loading. J Appl Physiol 1992; 72: 590-596.

39. Gottfried SB, Rossi A, Higgs BD. Non-invasive determination of respiratory system mechanics during mechanical ventilation for acute respiratory failure. Am Rev Respir Dis 1985; 131: 414-420.

40. Tobin MJ. Respiratory muscles in disease. Clin Chest Med 1988; 9: 263-286.

41. Begin R, Bureau MA, Lupien L, Limieux B. Control and modulation of respiration in Steinert's myotonic dystrophy. Am Rev Respir Dis 1980; 121: 281-289.

42. Gallagher CG, Im Hof V, Younes M. Effect of inspiratory muscle fatigue on breathing pattern. J Appl Physiol 1985; 59: $1152-1158$.

43. Cohen C, Zagelbaum G, Gross D, Roussos C, Macklem PT. Clinical manifestations of inspiratory muscle fatigue. $\mathrm{Am}$ J Med 1982; 73: 308-316.

44. Zhu E, Petrof BJ, Gea J, Comtois N, Grassino AE. Diaphragm muscle fiber injury after inspiratory resistive breathing. Am J Respir Crit Care Med 1997; 155: 1110-1116.

45. Jiang T-X, Reid WD, Road JD. Delayed diaphragm injury and diaphragm force production. Am J Respir Crit Care Med 1998; 157: 736-742.

46. Goldstone JC, Green M, Moxham J. Maximum relaxation rate of the diaphragm during weaning from mechanical ventilation. Thorax 1994; 49: 54-60.

47. Brochard L, Hart A, Lorini H, Lemaire F. Inspiratory pressure support prevents diaphragmatic fatigue during weaning from mechanical ventilation. Am Rev Respir Dis 1989; 139: 513-521. 
48. Le Bourdelles G, Viires N, Boczkowski J, Seta N, Pavlovic D, Aubier M. Effects of mechanical ventilation on diaphragmatic contractile properties in rats. Am J Respir Crit Care Med 1994; 149: 1539-1544.

49. Laghi F, Cattapan SE, Jubran A, et al. Is weaning failure caused by low-frequency fatigue of the diaphragm? Am J Respir Crit Care Med 2003; 167: 120-127.

50. Laghi F, Topeli A, Tobin MJ. Does resistive loading decrease diaphragmatic contractility before task failure? J Appl Physiol 1998; 85: 1103-1112.

51. Burrows B, Earle RH. Course and prognosis of chronic obstructive lung disease. A prospective study of 200 patients. $N$ Engl J Med 1969; 280: 397-404.

52. Lane DJ, Howel JBL, Giblin B. Relation between airways obstruction and carbon dioxide tension in chronic obstructive pulmonary disease. BMJ 1968; 3: 707-709.

53. Scott RW. Observations on the pathologic physiology of chronic pulmonary emphysema. Arch Intern Med 1920; 26: 544-560.

54. Christie RV. The elastic properties of emphysematous lung and their clinical significance. J Clin Invest 1934; 13: 295-321.

55. Robin ED, $\mathrm{O}^{\prime}$ Neill RP. The fighter versus nonfighter. Control of ventilation in chronic obstructive pulmonary disease. Arch Environ Health 1963; 7: 125-129.

56. Sorli J, Grassino A, Lorange G, Milic-Emili J. Control of breathing in patients with chronic obstructive pulmonary disease. Clin Sci Mol Med 1978; 54: 295-304.

57. Gorini M, Spinelli A, Ginnani R, Duranti R, Gigliotti F, Scano G. Neural respiratory drive and neuromuscular coupling in patients with chronic obstructive pulmonary disease. Chest 1990; 98: 1179-1186.

58. Topeli A, Laghi F, Tobin MJ. The voluntary drive to breathe is not decreased in hypercapnic patients with severe COPD. Eur Respir J 2001; 18: 53-60.

59. Begin P, Grassino A. Inspiratory muscle dysfunction and chronic hypercapnia in chronic obstructive pulmonary disease. Am Rev Respir Dis 1991; 143: 905-912.

60. Gorini M, Misuri J, Corrado A, et al. Breathing pattern and carbon dioxide retention in severe chronic obstructive pulmonary disease. Thorax 1996; 51: 677-683.

61. Rossi A, Gottfried SP, Zocchi L, et al. Measurement of static compliance of the total respiratory system in patients with acute respiratory failure during mechanical ventilation. $A m$ Rev Respir Dis 1985; 131: 672-677.

62. Coussa ML, Guerin C, Eissa NT, et al. Partitioning of work of breathing in mechanically ventilated COPD patients. J Appl Physiol 1993; 75: 1711-1719.

63. Sharp JT. The chest wall and respiratory muscles in airflow limitation. In: Roussos C, Macklem PT, eds. The Thorax. New York, NY, Marcel Dekker, 1985; pp. 1155-1202.

64. Duron B, Marlot D. The non-myelinated fibers of the phrenic and intercostal nerves in the cat. Z Mikrosk Anat Forsch 1980; 94: 257-268.
65. Hinsey JC, Hare K, Philips RA. Sensory components of the phrenic nerve of the cat. Proc Soc Exp Bio Med 1939; 41: 411-419.

66. Jammes Y, Balzamo E. Changes in afferent and efferent phrenic activities with electrically induced diaphragmatic fatigue. J Appl Physiol 1992; 73: 894-902.

67. Petrozzino JJ, Scardella AT, Edelman NH, Santiago TV. Respiratory muscle acidosis stimulates endogenous opioids during inspiratory loading. Am Rev Respir Dis 1993; 144: 607-615.

68. Kumazawa T, Tadaki E, Kim K. A possible participation of endogenous opiates in respiratory reflexes induced by thin fiber muscular afferents. Brain Res 1980; 199: 244-248.

69. Waldrop TG, Eldridge FL, Milhorn DE. Prolonged poststimulus inhibition of breathing following stimulation of afferents from muscle. Respir Physiol 1982; 50: 239-254.

70. Wanke T, Lahrmann H, Auinger M, et al. Endogenous opioid system during inspiratory loading in patients with type I diabetes. Am Rev Respir Dis 1993; 148: 1335-1340.

71. Vasilakopoulos T, Zakynthinos S, Roussos C. Strenuous resistive breathing induces proinflammatory cytokines and stimulates the HPA axis in humans. Am J Physiol 1999; 277: 1013-1019.

72. Kjoer A, Knigge U, Bach FG, Warberg J. Stress-induced secretion of pro-opiomelanocortin-derived peptides in rats: relative importance of anterior and intermediate pituitary lobes. Neuroendocrinology 1995; 61: 167-172.

73. Drenth JP, Van Uum SH, Van Deuren M, Pesman GJ, Van der ven-Jongekrijg J, Van der Meer JW. Endurance run increases circulating IL-6 and IL-1ra but downregulates ex vivo TNF- $\alpha$ and IL-1 $\beta$ production. J Appl Physiol 1995; 79: $1497-1503$.

74. Guillemin R, Vargo T, Rossier J. $\beta$-Endorphin and adrenocorticotropin are secreted concomitantly by the pituitary gland. Science 1977; 197: 1367-1369.

75. Watanabe TA, Morimoto A, Tan N, et al. ACTH response induced in capsaicin-desensitized rats by interleukin-1 or prostaglandin E. J Physiol (Lond) 1994; 457: 139-145.

76. Anzuetto A, Andrate FH, Maxwell LC, et al. Resistive breathing activates the glutathione redox cycle and impairs performance of the rat diaphragm. J Appl Physiol 1992; 72: 529-534.

77. Anzuetto A, Supinski GS, Levine SM, Jenkinson SG Mechanisms of disease: are oxygen derived free radicals involved in diaphragmatic dysfunction? Am J Respir Crit Care Med 1994; 149: 1048-1052.

78. Vasilakopoulos T, Katsaounou P, Karantza M-H, Kollintza A, Zakynthinos S, Roussos C. Strenuous resistive breathing induces plasma cytokines. Am J Respir Crit Care Med 2002; 166: 1-7.

79. Chroussos GP. The hypothalamic-pituitary-adrenal axis and immune mediated inflammation. N Engl J Med 1995; 332: $1351-1361$. 